International Journal of Engineering \& Technology, $10(1)(2021) 64-71$
International Journal of Engineering \& Technology
Website: www.sciencepubco.com/index.php/IJET
Research paper

\title{
Modeling temperature profile in mass concrete at early ages of cement hydration
}

\author{
Ugwuanyi Donald Chidiebere $^{1 *}$, Okafor Fidelis Onyebuchi ${ }^{1}$ \\ ${ }^{1}$ Department of Civil Engineering, University of Nigeria, Nsukka. Nigeria \\ *Corresponding author E-mail: chididonald1981@gmail.com
}

\begin{abstract}
Thermally induced cracks due to temperature gradient in mass concrete have adverse effects on its durability and service life. Heat released during the hydration of Portland cement in early age mass concrete can be quite excessive depending on the ambient temperature, cement content of the concrete mix and the size. Finite difference model using Crank Nicholson implicit method was developed based on the two dimensional unsteady state heat conduction. Optimized MATLAB based software was developed for simulation and data visualization. A mass concrete block cast with standard mix ratio and water cement ratio was used to verify the efficacy of the model. Type-K thermocouple and digital thermometer were used to monitor the temperature at time intervals. The temperature profile showed a hotter core and cooler surface except for the initial placement temperature, which exhibited a uniform temperature for all thermocouple locations. Peak temperature values were recorded within the first day of concrete placement. The model successfully predicted the temperature profile of the mass concrete at early ages of cement hydration. With the knowledge of the ambient temperature and the configuration of the mass concrete, the model can reliably predict the temperature profile from which potential for thermal cracks occurrence can be determined to enable suitable proactive preventive and control measures.
\end{abstract}

Keywords: Modeling; Temperature; Mass Concrete; Finite Difference; MATLAB; Software.

\section{Introduction}

Portland cement, when mixed with water releases heat, which is known as the heat of hydration, an exothermic reaction that occurs in cement pastes. This heat that is released due to hydration of cement leads to temperature increase within the mass concrete. For moderate size concrete members, the heat is liberated into adjacent soil and/or the air and the resulting temperature may not be a cause for concern. However, in the case of mass concrete, the heat may not be easily liberated and is therefore trapped within the concrete core. Temperature gradient occurs when the heat of hydration is released to immediate environment resulting in a lower surface temperature when compared to the concrete core. The concrete member will experience contraction at the surface and the interior having higher temperature due to heat being trapped within will offer restraint against the contraction action at the surface, which might result to surface cracks.

Modeling the generation and transfer of heat in early-age concrete is essential to understanding the behaviour of mass concrete [1]. Earlyage concrete or young hardening concrete is among the most challenging materials to model. The difficulties are due to a rather complex composite structure which is subject to transient conditions as cement hydration progresses [2]. [3] utilized heat and moisture transport model in hydrating concrete to predict heat generated during concrete hydration. [4] studied thermal crack of massive concrete structures using extended finite element method (XFEM) utilizing thermal fields and creep. [5] estimated cracking risk of concrete at early ages based on thermal stress analysis. [6] modeled early age thermal cracking in hardening concrete based on degree of hydration. [7] developed a model based on hydro-mechanical analysis of hydrating concrete structures which considered hydration heat, concrete composition, reinforcement, shrinkage and creep. [8] applied transient plane source measurement technique to assess the heat capacity and thermal conductivity of hydrating cement. [9] proposed a coupled thermo-chemo-mechanical model to determine the behaviour of early age concrete to simulate cement hydration, aging, damage and creep. [10] applied finite element simulation to predict early age concrete temperature distribution in thick rafts. The objective of the research is to develop a model to predict the temperature profile in mass concrete at early ages of cement hydration.

\section{Methodology}

A mass concrete block of dimension $1.1 \mathrm{~m}$ x $1.1 \mathrm{~m} \times 1.1 \mathrm{~m}$, mix ratio 1:2:4 and water cement ratio of 0.6 consisting of ordinary Portland cement, river sand and coarse aggregate of maximum size $40 \mathrm{~mm}$ was used to verify the model. Type-K thermocouples position as shown 
in Fig. 1 and digital thermometer (Fig. 2) were used to monitor the temperature within the concrete mass at time intervals of $0,6,12,18$, 24, 48, 72, 96, 120 and 144 hours respectively. Plywood formwork of $25 \mathrm{~mm}$ thickness (Fig. 3) internally surrounded by polystyrene sheet as insulation and the top surface of the cast concrete covered with $50 \mathrm{~mm}$ thick layer of sand.

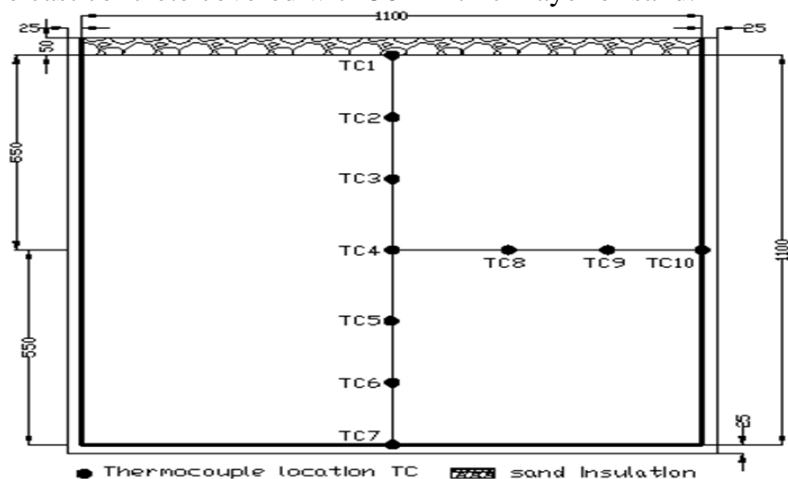

Fig. 1: Mass Concrete Block Showing the Layout of the Thermocouples. (Dimensions in Mm).

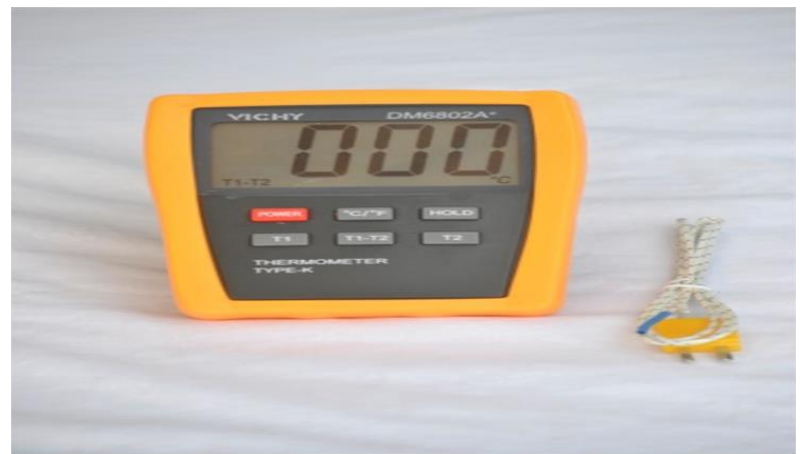

Fig. 2: Digital Thermometer and Type-K thermocouple.

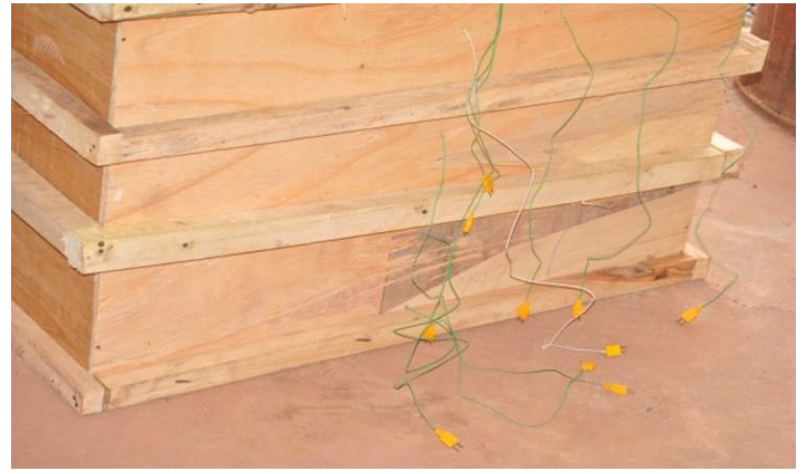

Fig. 3: Cast Mass Concrete Showing the Thermocouples.

\subsection{Model development}

The governing equation is that of two dimensional unsteady state heat conduction equation based on Fourier law of heat transfer shown in Equation 1. Finite difference solution of the governing equation using Crank Nicholson implicit finite difference method was determined applying the boundary and initial conditions.

$$
K\left(\frac{\partial^{2} T}{\partial x^{2}}+\frac{\partial^{2} T}{\partial y^{2}}\right)+q=\rho C p \frac{\partial T}{\partial t}
$$

$\rho$ is density of concrete $\left(\mathrm{kg} / \mathrm{m}^{3}\right), C_{P}$ is the specific heat capacity of concrete $\left(\mathrm{J} / \mathrm{kg} .{ }^{0} \mathrm{C}\right), q$ is the heat source intensity $\left(\mathrm{KJ} / \mathrm{m}^{3} . \mathrm{h}\right), \mathrm{K}$ is the thermal conductivity $\left(\mathrm{KJ} / \mathrm{m} \cdot \mathrm{h}^{0} \mathrm{C}\right), T$ is transient temperature of concrete $\left({ }^{0} \mathrm{C}\right)$ and $\mathrm{t}$ is time $(\mathrm{hrs})$.

At the spatial boundaries of the mass concrete, a constant temperature is assumed such that for thermal insulation, there exist the following boundary conditions.

$\mathrm{x}$-direction: $0 \leq \mathrm{x} \leq \mathrm{a}$, boundary conditions:

$T(0, y, t)=T(a, y, t)=T_{a}$

$\mathrm{y}$-direction: $0 \leq \mathrm{y} \leq \mathrm{b}$, boundary conditions: 
$T_{a}$ is the ambient temperature.

Initial conditions:

At $\mathrm{t}=0$, there is a uniform temperature such that

$$
T(x, y, 0)=T_{0}
$$

$T_{0}$ is initial placement temperature.

The general finite difference approximation of Equation (1) starts by forward difference for the time derivative and first forward difference and second central difference for the two spatial derivatives.

$$
\rho C p \frac{\left(T_{i 1 j}^{k+1}-T_{i 1 j}^{k}\right)}{\Delta t}=K \frac{\left(T_{i+1, j}-2 T_{i 1 j}+T_{i-1, j}\right)}{(\Delta x)^{2}}+K \frac{\left(T_{i, j+1}-2 T_{i 1 j}+T_{i, j-1}\right)}{(\Delta y)^{2}}+q_{i, j}^{k}
$$

The subscripts $\mathrm{i}, \mathrm{j}$ and $\mathrm{k}$ signifies the location in space and time steps.

$$
T_{i 1 j}^{k+1}-T_{i 1 j}^{k}=\frac{K \Delta t}{\rho C p(\Delta x)^{2}}\left(T_{i+1, j}-2 T_{i 1 j}+T_{i-1, j}\right)+\frac{K \Delta t}{\rho C p(\Delta y)^{2}}\left(T_{i, j+1}-2 T_{i 1 j}+T_{i, j-1}\right)+\frac{\Delta t}{\rho C p} q_{i, j}^{k}
$$

For purposes of simplification, let the location of the nodes $(i, j)$ be indicated as

$E \equiv i+1, j ; W \equiv i-1, j ; N \equiv i, j+1 ; S \equiv i, j-1 ; P \equiv i, j$ Then Equation (6) becomes;

$$
T_{P}^{k+1}-T_{p}^{k}=\frac{K \Delta t}{\rho C p(\Delta x)^{2}}\left[T_{E}-2 T_{P}+T_{W}\right]+\frac{K \Delta t}{\rho C p(\Delta y)^{2}}\left[T_{N}-2 T_{P}+T_{S}\right]+\frac{\Delta t}{\rho C p} q_{P}^{k}
$$

At the right of Equation (6), the temperature values are mean temperatures between time steps so that

$$
T_{n}=f T_{n}^{k+1}+(1-f) T_{n}^{k}
$$

Where $\mathrm{f}$ is the weighting factor. Applying Equations (7) and (8), the general finite difference approximation of the two-dimensional unsteady state heat conduction becomes;

$$
\begin{aligned}
& T_{P}^{k+1}-T_{p}^{k}=\frac{K \Delta t}{\rho C p(\Delta x)^{2}}\left[f T_{E}^{k+1}+(1-f) T_{E}^{k}+f T_{W}^{K+1}+(1-f) T_{W}^{K}-2 T_{P}+T_{W}-2 f T_{P}^{k+1}-2(1-f) T_{S}^{K}\right]+ \\
& \frac{K \Delta t}{\rho C p(\Delta y)^{2}}\left[f T_{N}^{k+1}+(1-f) T_{N}^{k}+f T_{S}^{K+1}+(1-f) T_{S}^{K}-2 f T_{P}^{K}\right]+\frac{\Delta t}{\rho C p} q_{P}^{K}
\end{aligned}
$$

(9)

Taking $\mathrm{f}$ as $\frac{1}{2}$, Equation (9) reduces to Crank-Nicholson implicit finite difference method.

$$
T_{P}^{k+1}-T_{p}^{k}=\frac{K \Delta t}{\rho C p(\Delta x)^{2}}\left[\frac{1}{2} T_{E}^{k+1}+\frac{1}{2} T_{E}^{k}+\frac{1}{2} T_{W}^{K+1}+\frac{1}{2} T_{W}^{K}-T_{P}^{k+1}-T_{P}^{K}\right] \frac{K \Delta t}{\rho C p(\Delta y)^{2}}\left[\frac{1}{2} T_{N}^{k+1}+\frac{1}{2} T_{N}^{k}+\frac{1}{2} T_{S}^{K+1}+\frac{1}{2} T_{S}^{K}-T_{P}^{k+1}-T_{P}^{K}\right]+\frac{\Delta t}{\rho C p} q_{P}^{K}
$$

$T_{P}^{k+1}\left[1+\frac{K \Delta t}{\rho C p(\Delta x)^{2}}+\frac{K \Delta t}{\rho C p(\Delta y)^{2}}\right]-\frac{K \Delta t}{2 \rho C p(\Delta x)^{2}}\left[T_{E}^{k+1}+T_{W}^{k+1}\right]-\frac{K \Delta t}{\rho C p(\Delta y)^{2}}\left[T_{N}^{k+1}+T_{S}^{k+1}\right]=T_{P}^{k}\left[1-\frac{K \Delta t}{\rho C p(\Delta x)^{2}}-\frac{K \Delta t}{\rho C p(\Delta y)^{2}}\right]$ $+\frac{K \Delta t}{2 \rho C p(\Delta x)^{2}}\left[T_{E}^{k}+T_{W}^{k}\right]+\frac{K \Delta t}{2 \rho C p(\Delta x y)^{2}}\left[T_{N}^{k}+T_{S}^{k}\right]+\frac{K \Delta t}{\rho C p} q_{P}^{K}$

\subsection{MATLAB based computer programe}

MATLAB based computer programe which is based on the Crank-Nicholson implicit finite difference numerical scheme was written to determine the nodal temperatures at different time steps based on Equation 11. The user interface for the programe is shown in Fig.4. 


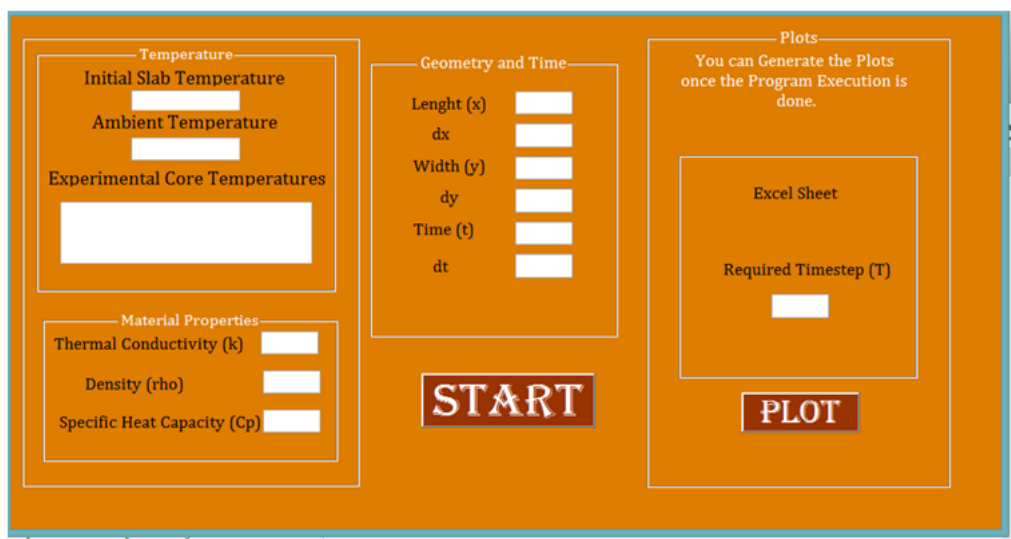

Fig. 4: Graphical User Interface (GUI) for the MATLAB Programe.

\section{Results}

The temperature values for the various thermocouple positions within the mass concrete block used for the model verification were recorded for the various time intervals. Fig.5a and Fig.5b shows the graphs of temperature against time for the various thermocouple locations. The zero hour temperature signifies the temperature of the mass concrete block immediately after placement which was found to be uniform throughout the various locations at $28^{\circ} \mathrm{C}$.

The thermocouple locations TC1 to TC7 in Fig. 5a signifies the top to the bottom of the mass concrete while locations TC4, TC8, TC9 and $\mathrm{TC} 10$ in Fig. $5 \mathrm{~b}$ are from the center (core) to the right side surface. The temperature profile indicates that the mass concrete exhibited higher temperature values within the core (ie TC3, TC4, TC5 and TC8) and the least values at locations close to the surface (ie TC1, TC7 and TC10) for all time intervals. After 120 hours of concrete placement, a constant temperature of $32^{\circ} \mathrm{C}$ was subsequently recorded for all thermocouple locations. The surface of the mass concrete in contact with the ground exhibited lower temperatures than other surfaces for most of the time intervals. Generally the temperature readings showed a rise from a uniform placement temperature of $28^{\circ} \mathrm{C}$ to the peak temperature of $51^{\circ} \mathrm{C}$ at the core after 24 hours and fall afterwards to $32^{\circ} \mathrm{C}$ at both 120 and 144 hours respectively.

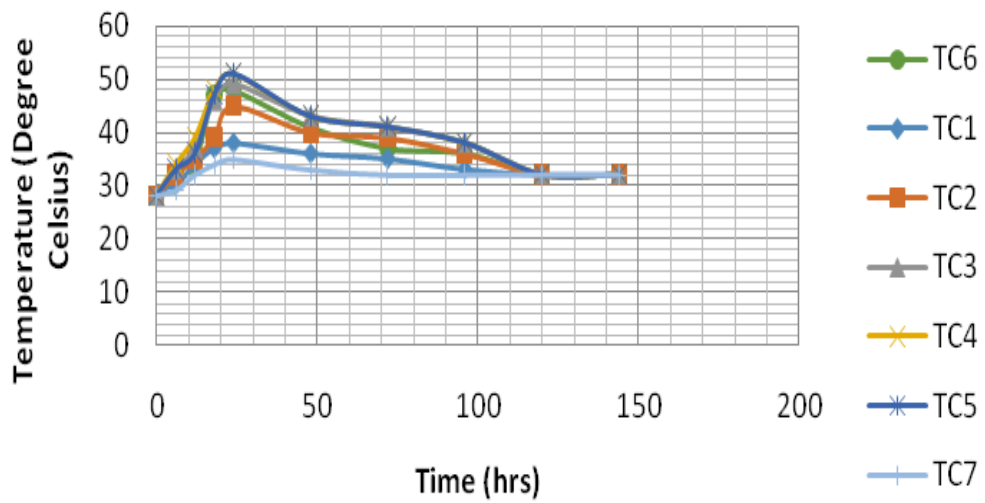

Fig. 5: A) Plot of Temperature against Time for Thermocouple Locations (TC1 to TC7).

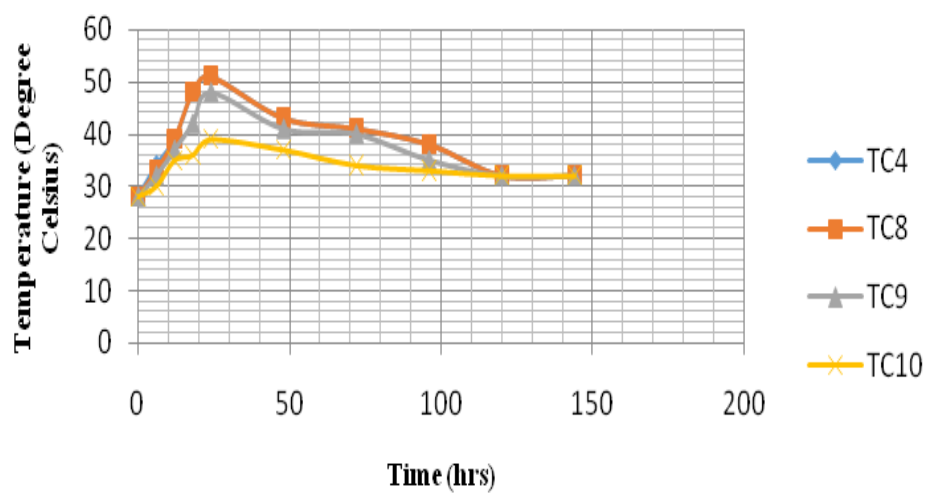

Fig. 5: B Plot of Temperature against Time for Thermocouple Locations (TC4, TC8, TC9 and TC10).

\subsection{Calibration}

The model parameters were calibrated by adopting definite values based on consideration of the material properties and the local conditions that affect the experimental procedures. Thermal conductivity values for normal weight concrete ranges from 7.1 to $10.6 \mathrm{KJ} / \mathrm{mh}^{0} \mathrm{C}$ and specific heat capacity ranges from 0.92 to $1.0 \mathrm{KJ} / \mathrm{Kg}^{0} \mathrm{C}$ according to ACI committee 207, 2005b in [11]. Values of $9 \mathrm{KJ} / \mathrm{mh}^{0} \mathrm{C}$ and 0.92 $\mathrm{KJ} / \mathrm{Kg}^{0} \mathrm{C}$ were respectively adopted for thermal conductivity and specific heat capacity. The density of fresh normal weight concrete is $2400 \mathrm{Kg} / \mathrm{m}^{3}$. For heat intensity, suzuki's model in [11] was adopted in which 


$$
q=20,000 e^{-0.9398-\frac{t}{24}}
$$

Average ambient temperature $\left(\mathrm{T}_{\mathrm{a}}\right)$ of $30^{\circ} \mathrm{C}$ and room temperature value of $26^{\circ} \mathrm{C}$ were used for the model verification and validation respectively. Initial temperature $\left(\mathrm{T}_{0}\right)$ is $28^{\circ} \mathrm{C}$.

\subsection{Verification}

A comparison of the model predicted temperature values and the observed experimental values shows that the model exhibited temperature values higher than the observed up till 48 hours after concrete placement and lower temperature values afterwards, Fig. 6 . The temperature values from the model had a constant temperature of $30^{\circ} \mathrm{C}$ after 72 hours of concrete placement.

A temperature difference of $0.53^{\circ} \mathrm{C}$ between 18 and 24 hours after concrete placement was recorded for the model. Generally, the model exhibited a steady temperature rise from $28^{\circ} \mathrm{C}$ at placement to $56.59^{\circ} \mathrm{C}$ at 24 hours and declined steadily to $32.02^{\circ} \mathrm{C}$ at 72 hours of placement and remained constant at $30^{\circ} \mathrm{C}$ afterwards. Both the model data and the experimental data have their highest temperature values of $56.59^{\circ} \mathrm{C}$ and $51^{\circ} \mathrm{C}$ at 24 hours of concrete placement respectively. The Fig. 8 to Fig. 12 show the 3D plots of temperature profile within the mass concrete at intervals of $0,24,48,72$ and 96 hours respectively.

Fig.7 shows the coefficient of determination $\mathrm{R}^{2}$ for the model verification with value of 0.631 which results to a correlation coefficient CORR value of 0.79 indicating that it within the acceptable limit for a good correlation.

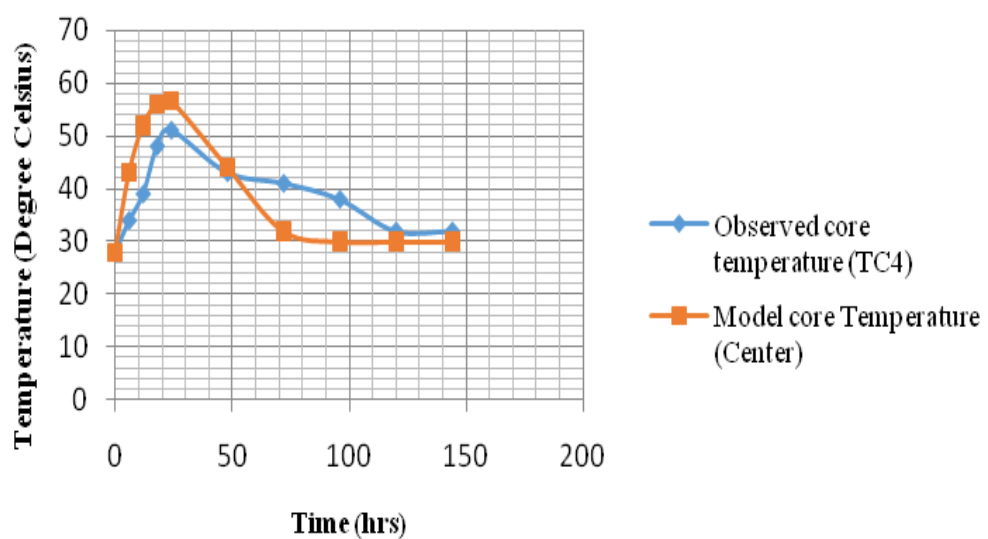

Fig.6: Temperature Time Relationship for Observed and Model Temperatures.

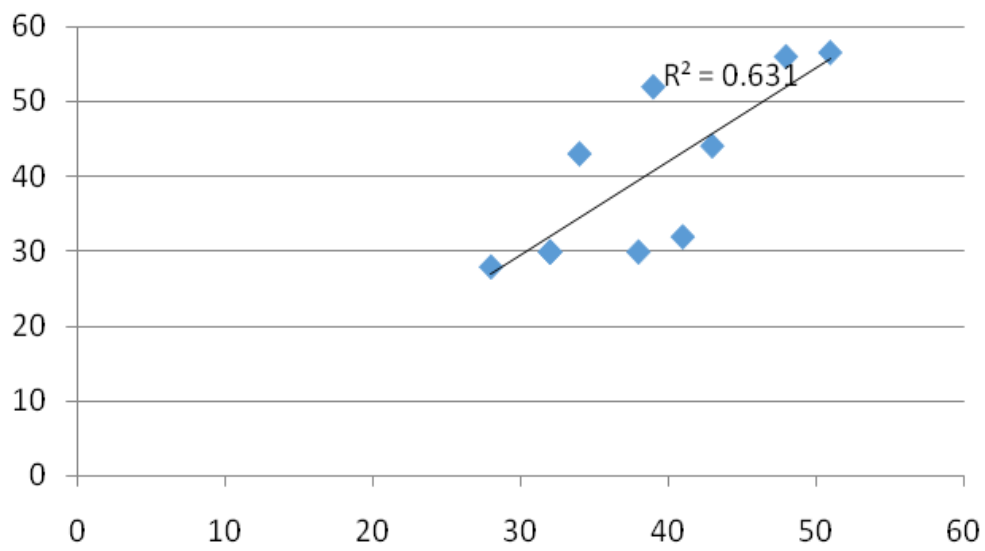

Fig. 7: Coefficient of Determination for Model Verification.

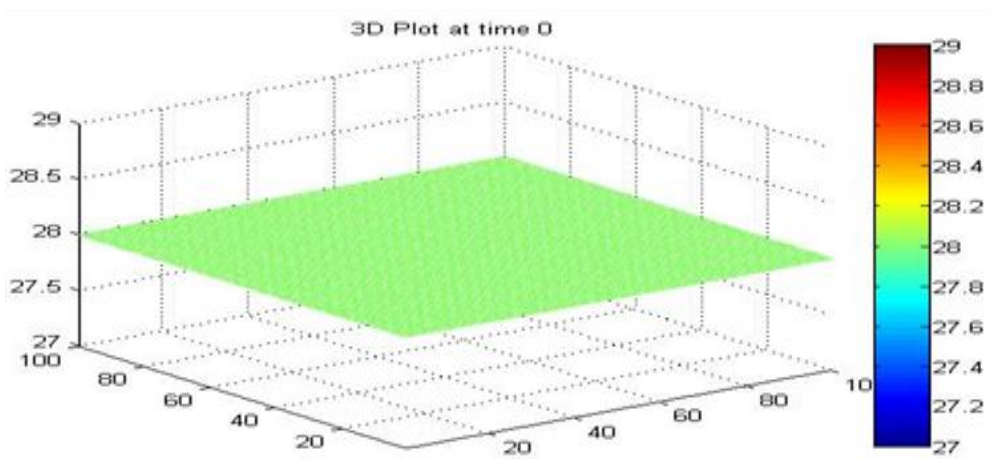

Fig. 8: 3D Plot of Temperature Profile at Initial Time of Concrete Placement. 


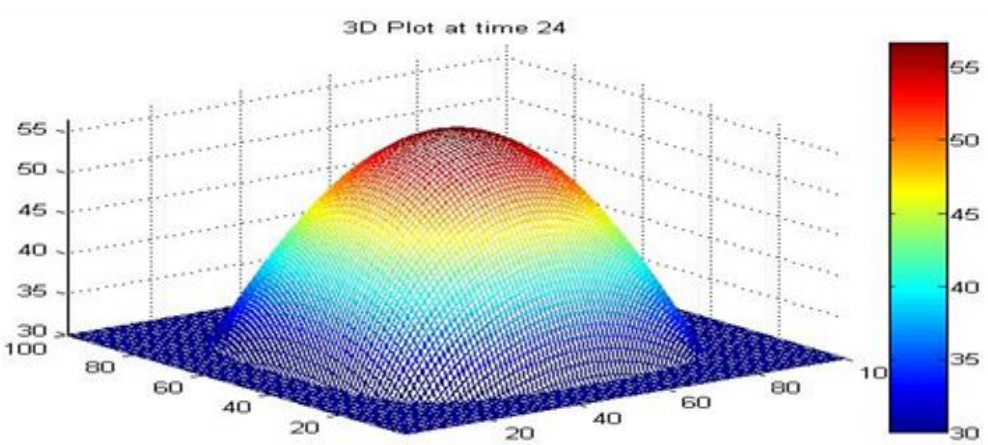

Fig. 9: 3D Plot of Temperature Profile at 24 Hours of Concrete Placement.

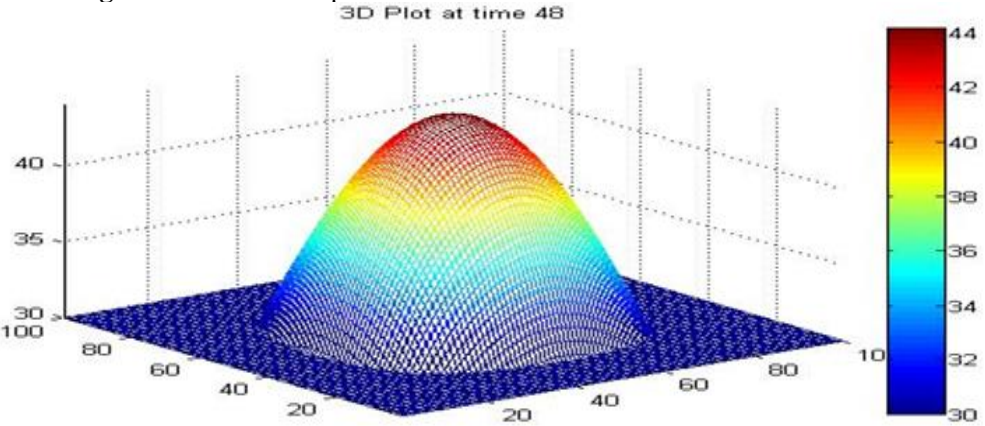

Fig. 10: 3D Plot of Temperature Profile at 48 Hours of Concrete Placement.

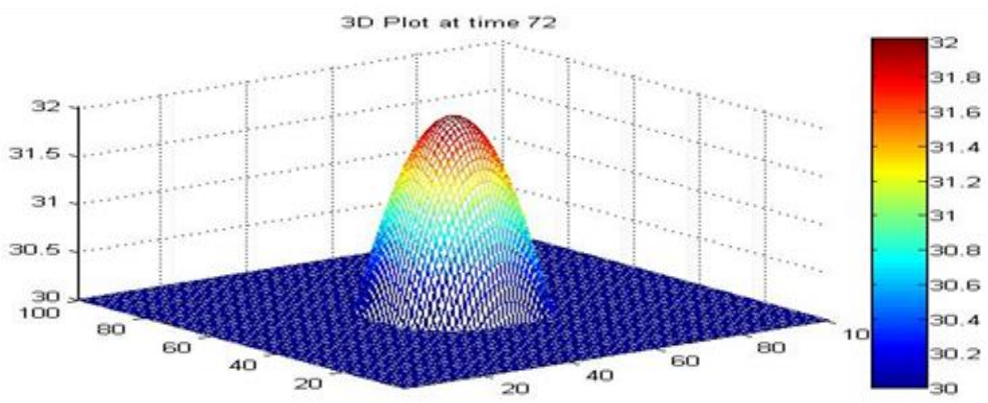

Fig. 11: 3D Plot of Temperature Profile at 72 Hours of Concrete Placement.

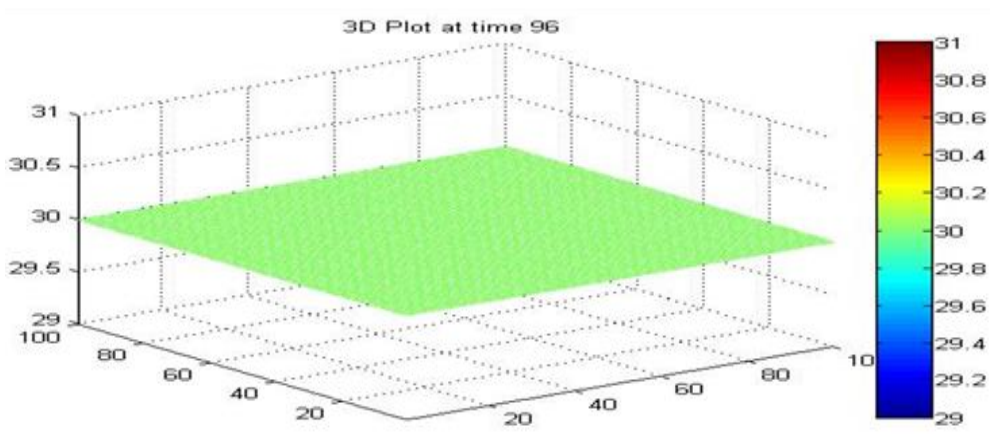

Fig. 12: 3D Plot of Temperature Profile at 96 Hours of Concrete Placement

\subsection{Validation}

The model developed was validated using temperature data from [12]. The boundary temperature is ambient temperature assumed to be room temperature of $26^{\circ} \mathrm{C}$. The graphs of the validation temperature data and the model in Fig. 13 show fairly identical plots. The peak temperature values for both the validation data and the model occurred at 24 hours of concrete placement of $74.32^{\circ} \mathrm{C}$ and $73.98^{\circ} \mathrm{C}$ respectively.

Fig. 14 shows the coefficient of determination $\mathrm{R}^{2}$ for the model validation with value of 0.975 which gives a correlation coefficient $C O R R$ value of 0.98 representing a very high correlation for the model validation. 


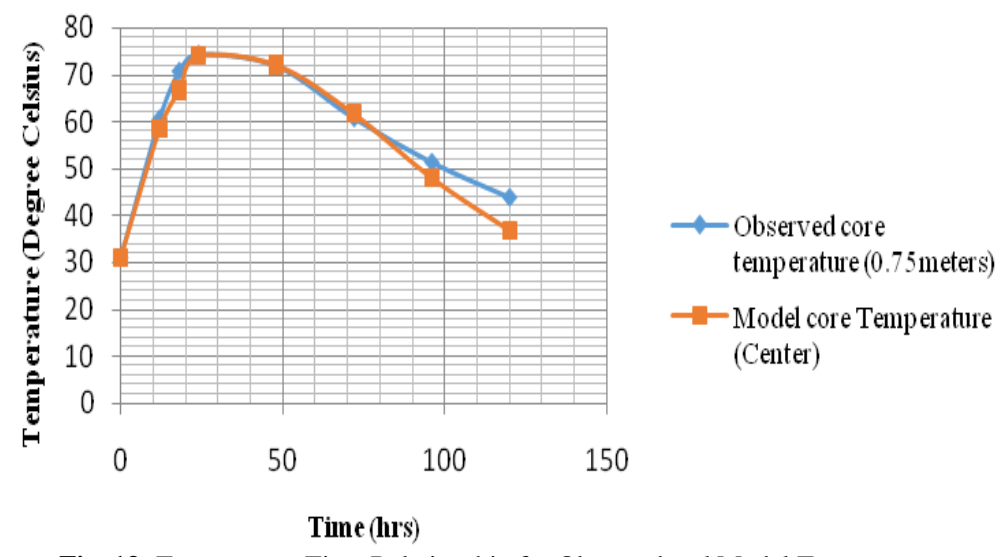

Fig. 13: Temperature Time Relationship for Observed and Model Temperatures.

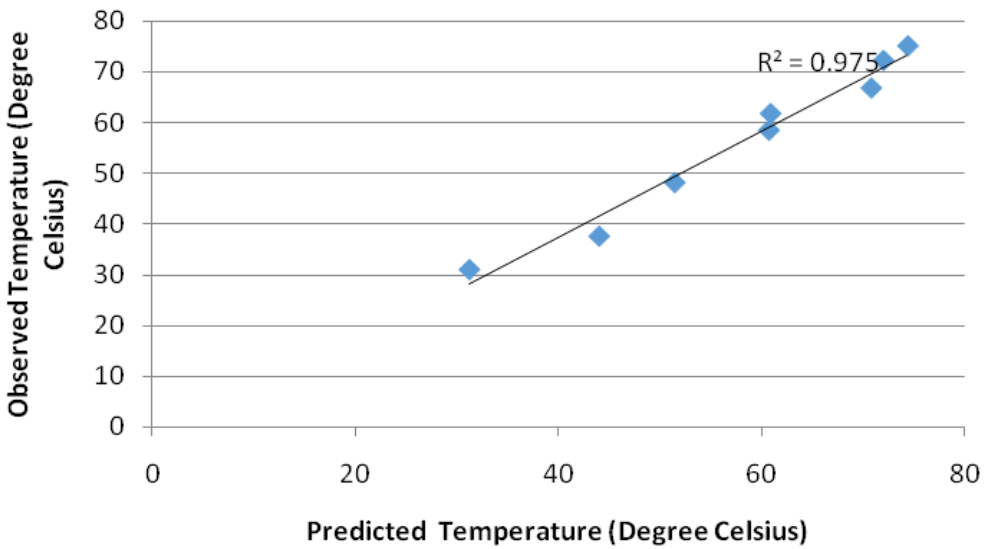

Fig. 14: Coefficient of Determination for Model Validation.

\section{Conclusion}

The thermal behaviour and temperature profile of mass concrete have been determined using a mass concrete block experiment. The initial temperature which is the placement temperature remained constant at all thermocouple locations in the mass concrete. Temperature difference between points in the mass concrete ceased to exit after 120 hours of concrete placement as a uniform temperature was recorded afterwards. The peak temperatures exhibited by the mass concrete occur within 24 hours after concrete placement. Crank Nicholson implicit finite difference method was successfully applied to the two dimensional unsteady state heat conduction within the mass concrete due to cement hydration. An optimized MATLAB based computer program was developed to determine the nodal temperatures at time intervals and for data visualization and simulation. With the ambient temperature and configuration of the mass concrete known, the temperature distribution at intervals of time can be predicted using the model developed. If the temperature profile in mass concrete can be predicted, then potentials for thermal cracks occurrence can be determined and appropriate preventive and control measure can be devised.

\section{Acknowledgement}

The authors appreciate the Department of Civil Engineering, University of Nigeria, Nsukka for their guidance and assistance towards the success of the research.

\section{References}

[1] I. Milovanovic, B. Pecure, I. Gabriel, Measuring thermal properties of hydrating cement $\quad$ pastes, 31st Cement and Concrete Science Conference, Novel Development and Innovation in Cementitious Materials, Imperial College London, United Kingdom, paper number XX (2011).

[2] B. Klemczak, A. Knoppik-Wróbel, Reinforced concrete tank walls and bridge abutments: early-age behaviour, Analytic Approaches and Numerical Models, Engineering Structures, 84(2015) 233-251. https://doi.org/10.1016/j.engstruct.2014.11.031.

[3] L. Jendele, V. Smilauer, J. Cervenka, Multi-scale analysis of heat transport in hydrating concrete structures, Proceedings of the Thirteenth International Conference on Civil, Structural and Environmental Engineering Computing, Civil-Comp Press, Stirlingshere, Scotland, paper 124(2011).

[4] G. Liu, Y. Hu, Q. Li, Z. Zuo, XFEM for thermal cracks of massive concrete, Mathematical Problems in Engineering, https://doi.org/10.1155/2013/343842.

[5] S. Wu, D. Huang, F. B. Liu, H. Zhao, P. Wang, Estimation of cracking risk of concrete at early age based on thermal stress analysis, J.Therm. Anal Calorim, Vol. 105, (2011) 171-186. https://doi.org/10.1007/s10973-011-1512-y.

[6] G. De Schutter, Modeling of early age thermal cracking in hardening concrete including creep and softening behaviour, Concrete Science and Engineering, 3 (2001) 146-150.

[7] J. Cervenka, L. Jendel, V. Smilauer, Modeling of crack development in young concrete in young concrete, VIII International Conference on Fracture Mechanics of Concrete and Concrete Structures, FraCos-8, (2017) 1-11.

[8] D. P. Bentz, Transient plane source measurement of the thermal properties of hydrating cement pastes, Materials and Structures, 40 (2007) $1073-$ 1080. https://doi.org/10.1617/s11527-006-9206-9. 
[9] M. Cervera, J. Oliver, T. Prato, Thermo-chemo-mechanical model for concrete: hydration and aging, Journal of Engineering Mechanics, 125 (9) (1999) 1018-1027. https://doi.org/10.1061/(ASCE)0733-9399(1999)125:9(1018).

[10] B. Kuriakose, B. N. Rao, G. R. Dodagoudar, Modeling of early age concrete temperature distribution in thick rafts, $5^{\text {th }}$ International Congress on Computational Mechanics and Simulation, (2014) 10 -13. https://doi.org/10.3850/978-981-09-1139-3 294

[11] H. Abeka, S. Agyeman, M. A. Asamoah, Thermal effect of mass concrete structures inthe tropics: experimental, modeling and parametric studies, Cogent Engineering, 4 (2017) 1278297. https://doi.org/10.1080/23311916.2016.1278297.

[12] W. G. J. Prasanna, A. P. Subhashini, Cracking due to temperature gradient in concrete, International on Sustainable Built Environment (ICSBE), Kandy, (2010) 496-504. 